\title{
Cotidiano da saúde
}

\section{SILVIA MARIA TEIXEIRA}

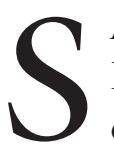

ão PAUlo, numa sexta-feira de fevereiro de 1999, "sem chuva, graças a Deus". A fila de cerca de 200 pessoas dobra o quarteirão. Estamos diante do prédio de quatro andares do Posto de Atendimento Médico do SUS (Sistema Único de Saúde), no bairro da Bela Vista. Aqui, cerca de 500 pessoas acorrem diariamente, em busca da assistência médica universal gratuita, inscrita como dever do Estado na Constituição Federal.

Rita de Cássia, copeira, 31 anos; Jane Cristina, arrumadeira, 23; e Ruth Maria, artesã, 43 anos, encabeçam a fila. As três têm em comum uma consulta na área da ginecologia. Delas, apenas Rita está vindo ao Posto pela primeira vez. "Talvez aqui seja assim porque tem mais gente, mas acho que fila existe em todos os estados", ela diz, num sotaque ainda forte. Mora em São Paulo há pouco tempo, vinda de Alagoas. "Tudo depende da hora em que a gente chega". E explica que, "para ser a primeira da fila", saíra de sua casa, na região de Santo Amaro, zona sul da capital, por volta das 4 h30 da madrugada.

"Eu saí cedo, também”, intervém na conversa a mineira Ruth. "Mas o que queria mesmo era um melhor atendimento. Às vezes você chega, e as fichas já acabou; aí muita gente volta. Já aconteceu comigo; e o atendimento é ruim, relâmpago. O médico mal tem tempo para olhar pra gente".

“As filas deveriam diminuir”, quem fala agora é Jane. “A gente não tem culpa de ganhar pouco e não poder pagar".

No meio da fila, que não pára de crescer, a conversa é praticamente a mesma. A maioria é de mulheres. Mas há também muitos homens e crianças. Os idosos só passam a ter uma fila preferencial depois de cadastrados. Enquanto isso não acontece, engrossam a fila comum.

Leonara Cândido Guedes, ascensorista, 34 anos, depõe: “Ontem, eu passei no PAS de Santo Amaro (o programa de saúde da Prefeitura paulistana), mas não consegui ser atendida. Então vim aqui; já tinha vindo outras vezes, trouxe meu filho também... Acho o atendimento bom. No pré-natal foram super atencioso. Só acho que devia ter uma fila para retorno".

Não é fácil abordar os últimos daquela fila. Está sempre chegando mais um, mais dois, mais três... São 7h10 da manhã. João da Cruz, pedreiro, 35 anos; Sílvia Ribeiro, ajudante de gráfica, 24; e Joana dos Santos, costureira 
desempregada, 50 anos, acabam de engrossar a fila. "Tenho fé de ser atendido ainda hoje", diz João, confiante na ficha de encaminhamento que recebeu de um hospital, também pertencente ao SUS.

Sílvia está vindo ao Posto pela segunda vez, e quer ser atendida por um outro médico. "O primeiro a me atender foi muito estúpido, não prestou atenção em nenhuma palavra do que eu disse. Eu nem comparo com o atendimento que tinha no meu plano de saúde, são realidades diferentes, mas pedi para mudar. As moças que fazem as fichas dão um bom atendimento".

"É preciso paciência", aconselha Joana. "Vim na quarta passada, mas não fui atendida. Vim de novo na quinta, e olha!, consegui fazer o exame".

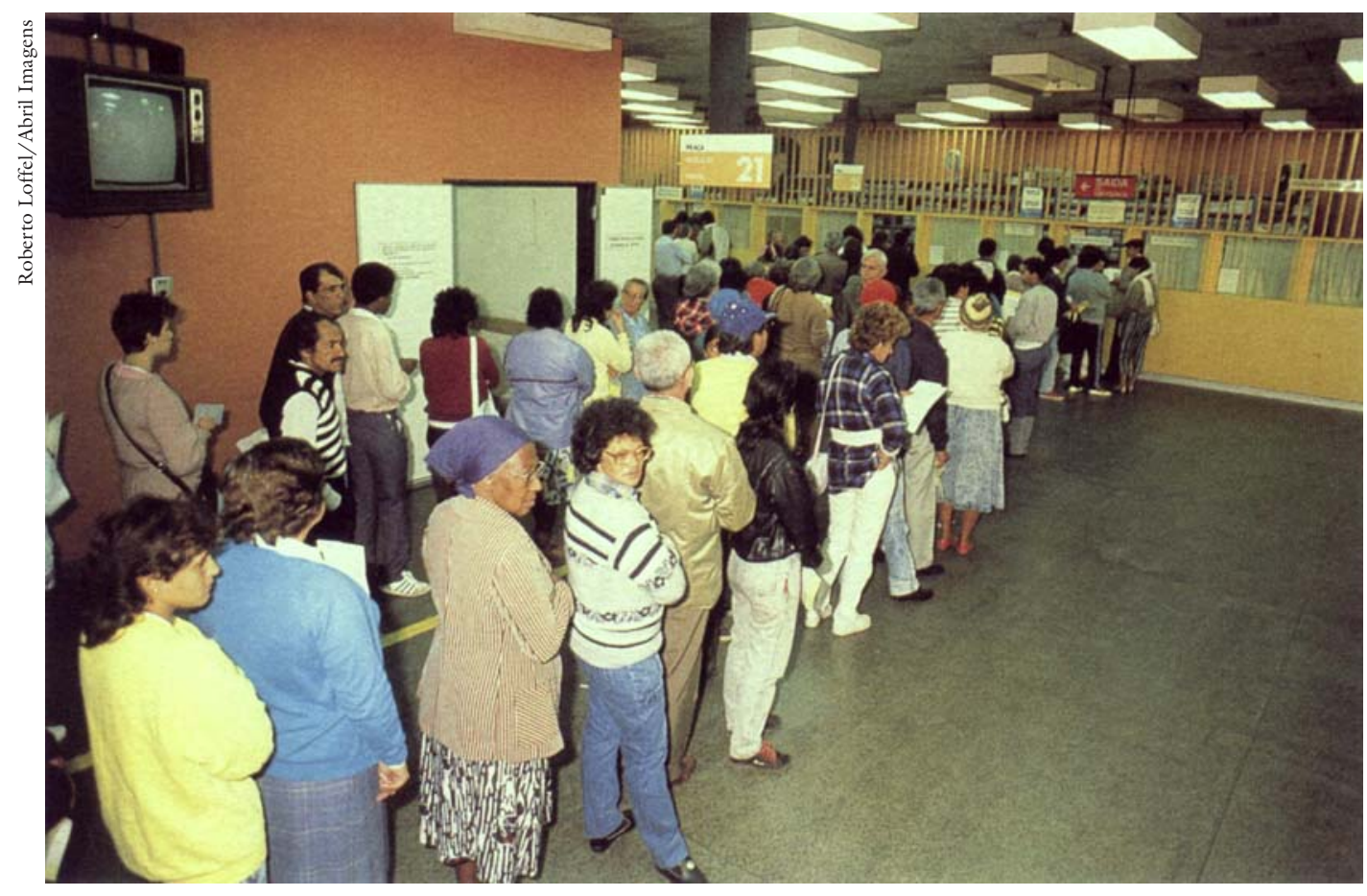

Fila dupla de pacientes do Hospital das Clínicas, SP

\section{Qualis}

"Uma grata surpresa". Não tive dúvida em começar assim o registro da visita que fiz à unidade VL Espanhola do Qualis, que atende a comunidade carente da Vila Cachoeirinha, na quinta-feira pós-carnaval. Não há filas exasperantes, mesmo nos dias de maior movimento. Com um sorriso no rosto, médicos e atendentes não escondem sua disposição de dar o melhor de si mesmos àquelas pessoas. 
As equipes multiprofissionais, compostas cada uma delas por um clínico geral, uma enfermeira, um auxiliar e um agente de saúde recrutado entre os próprios moradores da comunidade, percorrem regularmente as casas do bairro, enquanto no posto fixo é prestado o atendimento ambulatorial em 12 especialidades e realizados vários tipos de exames clínicos. O programa inclui também grupos de convivência, de relaxamento, de consciência corporal, de mutirões de limpeza e de reciclagem, e de teatro infantil e adulto.

Lany Valente, coordenadora regional do Qualis da Zona Norte - um projeto do SUS, dentro do programa Médico de Família -, diz que além de viável, em termos financeiros, o Qualis se caracteriza sobretudo pela humanização do atendimento médico, graças ao envolvimento que passa a existir entre a equipe multiprofissional e as famílias atendidas. "É freqüente ouvirmos um médico falando com prazer de sua profissão, pois aqui ele vê os resultados, o que é altamente gratificante", diz Lany. Mas sua opinião poderia parecer suspeita, devido ao cargo que ocupa. Será que os beneficiários do Qualis também pensam assim?

A unidade de Vila Cachoeirinha comemorou um ano de vida em fevereiro último. Neide Sueli A. F. da Câmara, 38 anos, que a freqüenta desde o início, e Maria José de Paula Lou, 68, que vem usando o serviço há nove meses, aceitaram dar o seu depoimento.

"O atendimento aqui é mais completo, mais humano", diz Maria José. Conta que o marido precisou de um exame complicado, cujo nome não lembra, mas que tinha junto a expressão "computadorizada", e houve o encaminhamento. "Ele também precisou do dentista, e foi completo", acrescentou.

Neide entra na conversa e conta uma longa história sobre o seu filho mais novo, que quebrou dois dentes-de-leite e um permanente em dois tombos que levou. "A dentista tirou o raio-x, viu que estava normal, e explicou que os dentes não crescem igual, mesmo que tenham caído juntos. Agora está crescendo".

Dona Maria José comparece ao posto a cada três meses, para fazer o acompanhamento de diabetes e hipertensão. "Eles atendem na hora, sem marcar com antecedência", explica. Diz que o médico que a atende, a quem se refere pelo nome, constatou recentemente que ela sofre também de labirintite, e que o remédio que usa não foi comprado na farmácia, mas dado pela unidade. "Aqui a gente tem tudo que precisa", dona Maria José continua em seus elogios. "O pessoal atende com bom humor, não maltrata. A gente só tem que agradecer esse atendimento, não é todo lugar que tem". 
E sobre o atendimento em casa? "Na minha rua duas pessoas têm, pois não podem se locomover", responde dona Maria José. E Neide Sueli completa: "Os médicos vão mesmo. Minha vizinha, que está na cadeira de rodas, recebe visita sempre."

\section{Lideranças comunitárias}

Líderes comunitários têm exercido um papel relevante para a melhoria do atendimento médico às faixas mais carentes da população. E estão na linha de frente de defesa do SUS. Eis os depoimentos colhidos de três destes líderes:

Marina Marques de Souza, vice-presidente da Federação Paulista de Associações de Moradores e presidente da Associação Feminina Vila AlpinaParque São Lucas: "Nossa luta pelo SUS é diária. Acreditamos que é a forma de ajudar nossa população, com investimentos em hospitais e com o atendimento à gestante e à criança, a partir do dinheiro arrecadado nos impostos que pagamos. Como pagar planos de saúde com tanto desemprego e com a miséria crescendo? Além do mais, os planos não cobrem tudo o que deveriam cobrir e ainda repassam para o sistema público os tratamentos mais caros. Estamos contentes com o atendimento que o SUS presta à gestante e à criança, mas nós sempre queremos mais.”

Galeno Silva, representante dos portadores de deficiência no Conselho Estadual de Saúde: "De forma geral, o atendimento ao portador de deficiência deve ser melhorado, principalmente porque existem certas especificidades no tratamento. Certos aspectos não são contemplados, como a questão da sexualidade do portador de deficiência. Há também algumas falhas no tocante à reabilitação. Nossa luta é para melhorar tudo isso. De qualquer forma, o SUS garante a eqüidade no atendimento."

Naelson Correia Guimarães, representante dos usuários no Conselho Estadual de Saúde: "Sou um defensor intransigente do SUS. Trata-se de uma grande conquista que precisa ser efetivamente implantada, pois sua importância cresce cada vez mais. Com a crise social e econômica que vivemos, há milhões e milhões de pessoas que não têm condições de pagar seguro saúde ou planos de saúde. A única saída para eles está no sistema público de saúde. Nossa maior luta agora é para melhorar o tratamento aos idosos, que continuam sendo vistos não como pessoas, mas como números.”

Silvia Maria Teixeira é jornalista e aprimoranda do Instituto de Saúde da Secretaria Estadual de Saúde, na área de saúde coletiva. 